University of Rhode Island

DigitalCommons@URI

\title{
Clinical validation of the "in silico" prediction of immunogenicity of a human recombinant therapeutic protein
}

\author{
E. Koren
}

Anne S. De Groot

University of Rhode Island, annied@uri.edu

V. Jawa

K. D. Beck

T. Boone

See next page for additional authors

Follow this and additional works at: https://digitalcommons.uri.edu/immunology_facpubs

This is a pre-publication author manuscript of the final, published article.

Terms of Use

All rights reserved under copyright.

\section{Citation/Publisher Attribution}

Koren, E., De Groot, A. S., Jawa, V., Beck, K. D., Boone, T., Rivera, D., Li, L., Mytych, D., Koscec, M., Weeraratne, D., Swanson, S., \& Martin, W. (2007). Clinical validation of the 'in silico' prediction of immunogenicity of a human recombinant therapeutic protein. Clinical Immunology, 124(1), 26-32. Available at: http://www.sciencedirect.com/science/article/pii/S1521661607011333

This Article is brought to you for free and open access by the Institute for Immunology and Informatics (iCubed) at DigitalCommons@URI. It has been accepted for inclusion in Institute for Immunology and Informatics Faculty Publications by an authorized administrator of DigitalCommons@URI. For more information, please contact digitalcommons-group@uri.edu. 


\section{Authors}

E. Koren, Anne S. De Groot, V. Jawa, K. D. Beck, T. Boone, D. Rivera, L. Li, D. Mytych, M. Koscec, D. Weeraratne, S. Swanson, and W. Martin

This article is available at DigitalCommons@URI: https://digitalcommons.uri.edu/immunology_facpubs/69 


\title{
Clinical validation of the "in silico" prediction of immunogenicity of a human recombinant therapeutic protein
}

\author{
ARTICLE in CLINICAL IMMUNOLOGY·AUGUST 2007 \\ Impact Factor: 3.67 · DOI: 10.1016/j.clim.2007.03.544 · Source: PubMed
}

CITATIONS

63

12 AUTHORS, INCLUDING:

\section{Eugen Koren}

Abbott Laboratories

27 PUBLICATIONS 1,309 CITATIONS

$$
\text { SEE PROFILE }
$$

Daniel T Mytych

Amgen

28 PUBLICATIONS 350 CITATIONS

SEE PROFILE 


\title{
Clinical validation of the "in silico" prediction of immunogenicity of a human recombinant therapeutic protein
}

\author{
E. Koren ${ }^{a, *}$, A.S. De Groot ${ }^{b, c}$, V. Jawa ${ }^{d}$, K.D. Beck ${ }^{d}$, T. Boone ${ }^{d}$, D. Rivera ${ }^{b}$, \\ L. Li ${ }^{d}$, D. Mytych ${ }^{d}$, M. Koscec ${ }^{d}$, D. Weeraratne ${ }^{d}$, S. Swanson ${ }^{d}$, W. Martin ${ }^{b}$ \\ a Scios Inc., 6500 Paseo Padre Pkway, Fremont, CA 94555, USA \\ ${ }^{\mathrm{b}}$ EpiVax Inc., 146 Clifford Street, Providence, RI 02903, USA \\ ' Brown University, Providence, RI 02912, USA \\ d Amgen Inc., One Amgen Center Drive, Thousand Oaks, CA 91320, USA
}

Received 15 January 2007; accepted with revision 17 March 2007

Available online 9 May 2007

\section{KEYWORDS \\ Immunogenicity \\ prediction; \\ Antibody response; \\ T-cell epitope; \\ HLA; \\ Immunoinformatics}

\begin{abstract}
Antibodies elicited by protein therapeutics can cause serious side effects in humans. We studied immunogenicity of a recombinant fusion protein (FPX) consisting of two identical, biologically active, peptides attached to human Fc fragment. EpiMatrix, an in silico epitopemapping tool, predicted promiscuous T-cell epitope(s) within the 14-amino-acid carboxyterminal region of the peptide portion of FPX. On administration of FPX in 76 healthy human subjects, 37\% developed antibodies after a single injection. A memory T-cell response against the above carboxy-terminus of the peptide was observed in antibody-positive but not in antibodynegative subjects. Promiscuity of the predicted T-cell epitope(s) was confirmed by representation of all common HLA alleles in antibody-positive subjects. As predicted by EpiMatrix, HLA haplotype DRB1*0701/1501 was associated with the highest T-cell and antibody response. In conclusion, in silico prediction can be successfully used to identify Class II restricted T-cell epitopes within therapeutic proteins and predict immunogenicity thereof in humans. (c) 2007 Published by Elsevier Inc.
\end{abstract}

\section{Introduction}

Virtually all therapeutic proteins induce some level of antibody response. Protein-induced immune responses can vary from low-level, low-affinity and transient IgM antibodies to high-level, high-affinity IgG antibodies. Antibodyrelated clinical sequelae also vary from none to severe, and

\footnotetext{
* Corresponding author.

E-mail address: ifica99@yahoo.com (E. Koren).
}

can occasionally be associated with life threatening side effects [1]. Antibody analyses from a number of clinical studies strongly suggest that serious side effects are associated with high levels of IgG antibodies [2-6]. Such an antibody response is T-lymphocyte driven and includes isotype switching and affinity maturation [7]. T-helper cells, a subset of T-lymphocytes that specifically recognize epitopes presented by antigen presenting cells (APCs) in the context of MHC (major histocompatibility complex) Class II molecules, are the major drivers of the mature antibody response. Protein therapeutics that express MHC Class II 
restricted T-helper epitopes are likely to elicit more frequent and mature antibody responses with IgG as predominant isotypes. These T-helper epitopes can be represented as linear sequences comprising 8 to 12 contiguous amino acids that fit into the MHC Class II binding groove. Over the last 10 years, a number of computer algorithms have been developed and used for detecting Class II epitopes within protein molecules of various origins (De Groot and Berzofsky [8] and the accompanying issue of Methods [9]). Such "in silico" predictions of T-helper epitopes have already been successfully applied in attempts to increase immunogenicity and efficacy of vaccines [10-12].

The relationship between T-cell epitopes and immune response has also been the subject of a number of investigations in the field of protein therapeutics. In some cases, therapeutic proteins have also been screened for Thelper epitopes in an attempt to evaluate their potential immunogenicity [13-16]. Obviously, reliable in silico prediction of helper epitopes would be of significant value in development of protein therapeutics. Such predictions would make it possible to meaningfully rank candidates at the pre-clinical stage of drug development or to reengineer proteins to make them less immunogenic. Furthermore, individuals at higher risk of developing T-cell-driven antibody responses to the protein therapeutic could be identified prospectively using HLA (human leukocyte antigen) typing, if certain HLA can be associated with T-cell response and higher neutralizing antibody titers, as recently described by Barbosa et al. [14]. The use of these methods in the context of clinical trials of protein therapeutics is rather recent and deserves further exploration.

In this study, we describe the in silico evaluation of a protein therapeutic in terms of its T-helper epitope content. At the time of the epitope analysis, this protein had also been administered to human subjects in a clinical trial. We were therefore, able to test subsequent immune responses in vivo and compare them with the EpiMatrix predictions of immunogenicity.

\section{Materials and methods}

\section{Human fusion protein}

A recombinant human fusion protein (FPX) consisting of a human Fc fragment fused with two identical 24-amino-acid peptides was generated as described previously [17]. Briefly, phage display peptide libraries (Dyax Corp.) were employed and panned against the targets. After several rounds of selection, the resulting target specific-binding clones were recovered and converted into peptide-Fc fusion proteins (by expressing the active peptides in Escherichia coli as fusions to the Fc portion of human IgG1). One of the peptide-Fc fusion proteins (termed FPX) with two identical 24-aminoacid peptides attached to the amino-terminal end of the human germ line Fc- $\gamma$ fragment was chosen for the study.

\section{Generation of FPX peptide fragments}

Solid-phase peptide synthesis In addition to the whole fusion protein, three peptides spanning amino acids 1-10 (aa 1-10), 11-24 (aa 11-24) and
1-24 (aa 1-24) of the FPX peptide portion were synthesized. These peptide fragments were prepared at $0.2-\mathrm{mmol}$ scale on a Symphony peptide synthesizer (Protein Technologies Inc., Tucson, AZ) or Odessey peptide synthesizer (CEM, Matthews, NC) employing Fmoc/OtBu protection strategy. All Fmoc amino acids were purchased from Midwest Biotech (Fishers, IN). Preloaded Fmoc-Glu (OtBu), Fmoc-Trp (Boc), Fmoc-Pro, Fmoc-Leu HMP resins were purchased from Midwest Biotech (Fishers, IN).

\section{Purification}

Crude peptide and HPLC pooled fractions were analyzed by analytical RP-HPLC with a Vydac (Hesperia, CA) 214TP ${ }^{\text {TM }}$ C18 column using linear gradients of $0-60 \% \mathrm{ACN}$ in $0.1 \%$ aqueous TFA over $30 \mathrm{~min}$, and a flow rate of $0.6 \mathrm{ml} / \mathrm{min}$. The largescale RP-HPLC was carried out with a Vydac 218TP C18 column (Vydac) by using a linear gradient of 5 to $40 \%$ ACN in $0.1 \%$ aqueous TFA over 50 min with a flow rate of $20 \mathrm{ml} / \mathrm{min}$.

\section{Mass spectral analysis}

HPLC-MS was performed with an API 150 (PerSeptive Biosystems) in conjunction with Waters analytical HPLC system (Waters Corporation, Milford, MA) by using YMC ODSAQ $\mathrm{C} 18$ column, with a linear gradient of $0 \%$ to $60 \% \mathrm{ACN}$ in $0.1 \%$ aqueous TFA over $12 \mathrm{~min}$ with a flow rate of $0.6 \mathrm{ml} / \mathrm{min}$.

\section{Human subjects and FPX dosing}

The primary objective of this study was to assess the safety and tolerability of FPX. The study included standard safety monitoring (e.g., collection of adverse experience reports; repeated clinical chemistry, hematology, urinalysis, electrocardiograms and other assessments typical for this stage of development) as well as assessment of the pharmacokinetic properties of FPX. Healthy human female and male subjects were dosed with FPX in a Phase 1, single dose, and placebocontrolled, randomized, blinded, sequential dose escalation study. All subjects provided informed consent for participation in the study including HLA typing, anti-FPX antibody assays and T-cell assays. The study enrolled 76 subjects aged 18 to 55 years. In total, 36 subjects received a single dose of FPX intravenously and 40 subjects received FPX subcutaneously. Blood samples for analysis of anti-FPX antibodies were collected from all subjects on day 1 prior to dosing and on day 42 after dosing. In addition, eleven antibody-positive and 4 antibody-negative subjects agreed to provide additional blood samples for the in vitro PBMC studies with the FPX peptide fragments and HLA typing at the 6 months follow-up visit.

\section{Prediction and characterization of T-helper epitopes}

The peptide portion of the FPX fusion protein (FPX peptide) was screened for potential immunogenicity using previously published EpiMatrix System [18,19]. Briefly, the 24-aminoacid sequence was parsed into overlapping 9-mer frames where each frame overlaps the last by eight amino acids. Each frame was then scored for predicted binding to each of eight common Class II HLA alleles (DRB1*0101, DRB1*0301, DRB1*0401, DRB1*0701, DRB1*0801, DRB1*1101, DRB1*1301, and DRB1*1501). Due to their prevalence and their difference 
from each other, these eight alleles cover around $97 \%$ of human populations worldwide [20].

EpiMatrix raw binding score predicted for each 9-mer sequence was normalized with respect to a distribution of scores derived from a very large set $(N>10,000)$ of randomly generated 9-mer sequences. This results in a " $Z$ " score for each analyzed 9-mer. The $Z$ score determines the position of a 9-mer relative to the distribution of all binding scores generated for the random 9-mer sequences. Any peptide scoring above 1.64 on the EpiMatrix " $Z$ " scale (approximately the top $5 \%$ of the random peptide set) has a significant chance of binding to the MHC molecule for which it was predicted. Peptides scoring above 2.32 on the scale (the top 1\%) are extremely likely to bind; most published T-cell epitopes fall within this range of scores. Therefore, the higher the $Z$ score, the higher is the probability that a peptide will be presented to T-cells by the antigen presenting cells (APCs). Previous studies have demonstrated that EpiMatrix accurately predicts published MHC ligands and T-cell epitopes [21-23].

\section{Antibody detection and characterization}

\section{Antibody detection}

Antibodies directed against FPX were detected using a validated surface plasmon resonance (SPR)-based biosensor immunoassay using the Biacore $3000^{\mathrm{TM}}$ instrument (Biacore, Inc., Uppsala, Sweden) as previously described [24,25]. In brief, FPX peptide was covalently immobilized onto the flow cell of a CM-5 sensor chip using standard amine coupling chemistry. Human serum samples were injected across the FPX surface followed by the goat anti-human $\lg \mathrm{F}\left(\mathrm{ab}^{\prime}\right)_{2}$ antibody to confirm the antibody nature of the material bound to the FPX surface. The change in the SPR signal resulting from the bound human antibody and anti-human secondary antibody was reported in relative response units (RU). Serum samples were reported "reactive" for anti-FPX antibodies if the combined sample and confirmatory antibody binding (in RU) was greater than or equal to the validated threshold value (in RU). Samples below this threshold value were reported antibody-negative. All "reactive" samples were reported as positive if the combined sample and confirmatory binding of the post-dose sample was at least 2 -fold greater than the combined sample and confirmatory binding of the pre-dose sample.

\section{Antibody characterization}

Serum samples from eleven antibody-positive (5 IV and 6 SC dosed) subjects who agreed to provide additional blood samples for the in vitro T-lymphocyte studies with the FPX peptide fragments and HLA typing were characterized to determine the antibody isotype.

\section{Relative antibody concentration}

A rabbit polyclonal affinity-purified anti-FPX antibody (prepared at Amgen) was spiked into normal human serum and serially diluted to achieve calibrator concentrations ranging from 0.2 to $50 \mu \mathrm{g} / \mathrm{ml}$. The binding of each calibrator to the immobilized FPX was analyzed as described, expressed in RUs and plotted against the antibody concentration. The relative antibody concentration for each clinical sample was extrapolated from the calibrator curve and expressed in $\mu \mathrm{g} / \mathrm{ml}$ of anti-FPX antibody. The limit of detection of this assay was validated at $800 \mathrm{ng} / \mathrm{ml}$ of anti-FPX antibodies in neat human serum. Concentrations below $800 \mathrm{ng} / \mathrm{ml}$ were not detectable due to the background observed in drug-naive normal human sera.

\section{Antibody isotype determination}

The commercial (ICN Biomedicals; anti-human IgG, 8029-FICN; anti-human IgM M2110168; anti-human IgE, 8646F-ICN; anti-human IgA, 8647-F-ICN) isotype reagents were used. Each clinical sample was injected across the immobilized peptide portion of FPX on the sensor chip followed by the sequential injection of the anti-lgA, IgE, IgM and then the IgG antibody. Report points were taken before and after each injection and the difference was recorded in relative RUs. Binding of each isotype-specific reagent (in RU) greater than $100 \mathrm{RU}$ from the RUs recorded after sample binding, was reported as positive for the qualitative identification of the specific antibody isotype.

\section{HLA typing}

HLA typing was carried out by the National Histocompatability Laboratory division of the American Red Cross using IsoCards according to the protocol supplied by the Red Cross. Thirty to forty microliters of blood was obtained from each subject by finger prick. Blood samples were placed on the IsoCard using a pipette. The samples were then allowed to air dry and individually sealed in plastic bags. Each sample was then shipped to the American Red Cross (National Histocompatibility Laboratory at the University of Maryland Medical System) for processing and HLA typing.

\section{ELISPOT assays}

Peripheral blood mononuclear cells (PBMC) were isolated from FPX-treated subjects' heparinized peripheral blood samples by Ficoll separation and cryopreserved in 10\% DMSO (dimethyl sulfoxide) in liquid nitrogen. For the assay, the PBMCs were quickly thawed at $37{ }^{\circ} \mathrm{C}$, diluted in $15 \mathrm{ml}$ of RPMI supplemented with $10 \%$ heat-inactivated human serum (Valley Biomedical), spun at $300 \times \mathrm{g}$ for $20 \mathrm{~min}$, decanted, and resuspended in RPMI supplemented with $10 \%$ heatinactivated human serum. The cells were then plated at $1 \times 10^{7}$ cells/well in a 12 -well tissue culture dish (Corning) and placed in a $37{ }^{\circ} \mathrm{C}$ incubator with $5 \% \mathrm{CO}_{2}$. After $24 \mathrm{~h}$, $10 \mu \mathrm{g} / \mathrm{ml}$ of the study peptides was added to the wells. PHA $(10 \mu \mathrm{g} / \mathrm{ml})$ was added to positive control and the culture medium to the negative control wells. On Day 2, $10 \mathrm{U} / \mathrm{ml} \mathrm{IL}-2$ and $20 \mathrm{ng} / \mathrm{ml} \mathrm{IL-7} \mathrm{(R \& D} \mathrm{Systems)} \mathrm{were} \mathrm{added} \mathrm{to} \mathrm{each} \mathrm{of} \mathrm{the}$ wells. Cells were incubated for 7 days, with half the media being replaced on Day 4 with fresh media containing the interleukins.

On Day 7, the PBMCs were harvested and plated at $2 \times 10^{5}$ cells per well in separate ELISPOT plates pre-coated with monoclonal antibodies to INF- $\gamma$ and IL-4 respectively (MabTech). Target peptide was added to each test well at $10 \mu \mathrm{g} / \mathrm{ml}$ and the final volume was adjusted with medium to $200 \mu \mathrm{l} /$ well. This was followed by the 48 -h incubation at $37{ }^{\circ} \mathrm{C}$ and $5 \% \mathrm{CO}_{2}$. Positive control wells treated with $10 \mu \mathrm{g} / \mathrm{ml}$ PHA and negative controls with $10 \mu \mathrm{l}$ PBS were incubated under identical conditions. Cells were discarded 
Table 1 EpiMatrix $Z$ scores for 9-mer sequences of the peptide portion of the FPX molecule

\begin{tabular}{|c|c|c|c|c|c|c|c|c|c|c|}
\hline $\begin{array}{l}\text { Class II } \\
\text { alleles }\end{array}$ & $\begin{array}{l}\text { DRB1 } \\
{ }^{*} 0101\end{array}$ & $\begin{array}{l}\text { DRB1 } \\
{ }^{*} 0301\end{array}$ & $\begin{array}{l}\text { DRB1 } \\
{ }^{*} 0401\end{array}$ & $\begin{array}{l}\text { DRB1 } \\
{ }^{*} 0701\end{array}$ & $\begin{array}{l}\text { DRB1 } \\
{ }^{*} 0801\end{array}$ & $\begin{array}{l}\text { DRB1 } \\
{ }^{*} 1101\end{array}$ & $\begin{array}{l}\text { DRB1 } \\
{ }^{*} 1301\end{array}$ & $\begin{array}{l}\text { DRB1 } \\
{ }^{*} 1501\end{array}$ & Hit & Average \\
\hline AA sequence & Z score & Z score & Z score & Z score & Z score & Z score & Z score & Z score & Count & Z score \\
\hline $1-9$ & -0.25 & -0.51 & -0.38 & 0.23 & 1.05 & -0.24 & 0.3 & -0.2 & 0 & 0 \\
\hline $2-10$ & -2.83 & 0.7 & -2.03 & -0.89 & -1.3 & -1.72 & -1.53 & -1.36 & 0 & -1.37 \\
\hline $3-11$ & 0.17 & -0.4 & -0.54 & -0.78 & -1.92 & -1.54 & -0.77 & -0.44 & 0 & -0.78 \\
\hline $4-12$ & -0.36 & -1.01 & -1.15 & -0.01 & -1.25 & 0.47 & -0.17 & -0.72 & 0 & -0.53 \\
\hline $5-13$ & -0.85 & -1.45 & -0.54 & -1.07 & -0.58 & -0.84 & -2.55 & 0.06 & 0 & -0.98 \\
\hline $6-14$ & -1.15 & 1.79 & -0.01 & -0.83 & -0.75 & -1.17 & 0.07 & -0.78 & 1 & -0.35 \\
\hline $7-15$ & -1.57 & -0.07 & -0.24 & 0.03 & -1.04 & -0.36 & 0.52 & -0.43 & 0 & -0.39 \\
\hline $8-16$ & 0.63 & 0.47 & -0.05 & -1.14 & -0.39 & -0.11 & -0.96 & 0.38 & 0 & -0.15 \\
\hline $9-17$ & 1.34 & -0.78 & -0.64 & 1.16 & -0.18 & -0.61 & -0.34 & 0.61 & 0 & 0.07 \\
\hline $10-18$ & 1.66 & 0.69 & 0.94 & 1.61 & 1.06 & 1.73 & 1.21 & -0.07 & 2 & 1.1 \\
\hline $11-19$ & 0.2 & 1.84 & -0.2 & -0.19 & 1.85 & 0.95 & 2.49 & 2.31 & 4 & 1.15 \\
\hline $12-20$ & 0 & 0.8 & 0.09 & -0.45 & 0.8 & 0.62 & 1.02 & 1.64 & 0 & 0.56 \\
\hline $13-21$ & 0 & -0.43 & 0.39 & -0.27 & 1.24 & 0.2 & 0.41 & 0.33 & 0 & 0.23 \\
\hline $14-22$ & 2.75 & 0.83 & 1.87 & 1.57 & 1.69 & 2.1 & 0.9 & 1.01 & 4 & 1.59 \\
\hline $15-23$ & 2.53 & 1.9 & 1.19 & 3.35 & 1.89 & 2.44 & 1.5 & 2.94 & 6 & 2.22 \\
\hline $16-24$ & -0.47 & -0.69 & -0.91 & -0.59 & -1.19 & -2.02 & -0.54 & 0.06 & 0 & -0.8 \\
\hline $\begin{array}{l}\text { Maximum } \\
\text { score }\end{array}$ & 2.75 & 1.9 & 1.87 & 3.35 & 1.89 & 2.44 & 2.49 & 2.94 & - & - \\
\hline
\end{tabular}

ITop $5 \%$ of $Z$ scores ITop $1 \%$ of $Z$ scores.

after the incubation and plates were washed with $0.05 \%$ PBST, incubated with HRP-conjugated mouse polyclonal anti-human INF- $\gamma$ or mouse anti-human IL-4 secondary antibody for $2 \mathrm{~h}$ at room temperature, washed with PBS and developed by the addition of the TMB substrate. After $15 \mathrm{~min}$, plates were washed with de-ionized water and allowed to air dry. The plates were subsequently screened for spot forming cells (SFC) by a Zeiss automated spot counter (Zellnet). Final results were expressed in terms of ratios between the numbers of SFCs in wells incubated with peptides or PHA and those counted in the negative control wells containing PBS.

\section{Statistical analysis}

Differences between the cytokine SFC ratios were tested by Wilcoxon's Exact test.

\section{Blinding of laboratory personnel to clinical data}

All four major components of this study were carried out in three different laboratories in a completely blinded fashion. EpiVax staff conducted in silico epitope prediction as well as in vitro PBMC challenge tests with no knowledge of the antibody or the HLA results. Similarly, HLA typing at the Red Cross laboratory and antibody analysis at Amgen's Clinical Immunology laboratory were also performed by personnel who were blinded to the results of the epitope prediction and PBMC testing results until the end of the study.

\section{Results}

\section{Prediction of T-cell helper epitopes}

The complete 24-amino-acid sequence of the FPX peptide was screened for predicted immunogenicity using EpiMatrix.
As described above, the peptide sequence was parsed into overlapping 9-mer frames and each frame was screened against EpiMatrix matrices developed for a panel of eight of the most common Class II HLA alleles. In total, 128 frameby-allele assessments were performed. Results of the EpiMatrix analysis are shown in Table 1. Overall, 17 allelespecific 9-mer frames showed EpiMatrix $Z$ scores above the predetermined cutoff value of 1.64 (positive EpiMatrix scores). Eleven of the positive frame-by-allele scores fell within the top $5 \%$ of the $Z$ score distribution established for the random peptides and 6 scored above 2.32, which placed them in the top $1 \%$ range of the $Z$ score distribution. All of these 6 highly scoring frames were located in the carboxy-terminal region of the peptide comprising amino acids $11-23$.

Furthermore, the carboxy-terminal region (aa 11-23) scored highly $(Z>2.32)$ with five separate HLA alleles (DRB1*0701, *1501, *0101, "1301, *1101), suggesting that this peptide had a significant potential to be presented by five different HLA molecules to T-cells. This pattern is characteristic of promiscuous epitopes that are immunogenic for a broad cross-section of individuals in any human population [20].

\section{Antibodies in subjects dosed with FPX}

Thirty seven percent of all subjects developed detectable antibodies after a single injection of FPX. The incidence of $40 \%$ was somewhat higher in SC-dosed subjects compared to the $33 \%$ observed in IV-dosed subjects. Both IV and SC subjects showed similar ranges of antibody concentrations ( $\sim 5$ to 20 and $\sim 4$ to $19 \mu \mathrm{g} / \mathrm{ml}$ respectively). Based on analyses of eleven antibody-positive subjects (5 IV and 6 SC dosed) who agreed to provide additional blood samples for the antibody characterization and in vitro lymphocyte studies, all of these subjects' antibodies were of the lgG isotype. 
Table 2 HLA DRB1* haplotypes, antibody levels and in vitro secretion of IFN- $\gamma$ and IL-4 by PBMCs of antibody positive and antibody negative subjects dosed with FPX

\begin{tabular}{|c|c|c|c|c|c|c|c|c|}
\hline \multirow{3}{*}{$\begin{array}{l}\text { Subject } \\
\text { ID }\end{array}$} & \multirow[t]{3}{*}{ HLA DRB1* } & \multirow{3}{*}{$\begin{array}{l}\text { Antibody } \\
\text { concentration } \\
(\mu \mathrm{g} / \mathrm{ml})\end{array}$} & \multicolumn{2}{|c|}{ aa $1-10$} & \multicolumn{2}{|c|}{ aa $11-24$} & \multicolumn{2}{|c|}{ aa $1-24$} \\
\hline & & & INF- $\gamma$ & IL-4 & INF- $\gamma$ & IL-4 & INF- $\gamma$ & IL-4 \\
\hline & & & \multicolumn{2}{|c|}{ SFC ratio } & \multicolumn{2}{|c|}{ SFC ratio } & \multicolumn{2}{|c|}{ SFC ratio } \\
\hline 1038 & $0701 / 1501$ & 20.20 & 1.88 & 0.79 & 26.00 & 89.00 & 34.52 & 92.40 \\
\hline 1128 & $0101 / 1301$ & 1.50 & 1.50 & 1.75 & 9.90 & 4.70 & 26.61 & 30.10 \\
\hline 1163 & $0101 / 1701$ & 1.03 & 0.66 & 1.36 & 14.60 & 6.80 & 16.80 & 14.50 \\
\hline 1060 & 0405/0101 & 1.11 & 1.35 & 1.23 & 6.00 & 4.68 & 9.41 & 7.06 \\
\hline 1148 & $0301 / 0701$ & 5.60 & 1.16 & 0.88 & 1.74 & 2.60 & 2.44 & 3.90 \\
\hline 1109 & $0301 / 1101$ & 1.20 & 1.68 & 1.53 & 2.70 & 1.60 & 6.60 & 2.62 \\
\hline 1070 & $0101 / 0103$ & 2.80 & 1.16 & 0.52 & 2.00 & 3.34 & 1.67 & 1.96 \\
\hline 1122 & $0101 / 1401$ & 1.14 & 1.15 & 1.18 & 1.10 & 2.40 & 1.53 & 3.15 \\
\hline 1153 & 0401 & 1.80 & 1.03 & 1.09 & 0.76 & 0.83 & 7.01 & 1.18 \\
\hline 1120 & $1104 / 1503$ & 0.82 & 1.01 & 1.46 & 1.11 & 1.70 & 1.23 & 1.62 \\
\hline 1131 & $0404 / 1501$ & 2.70 & 1.45 & - & 1.50 & - & 1.70 & - \\
\hline 1136 & 0102/0301 & $\mathrm{n} / \mathrm{a}$ & 0.81 & 0.74 & 1.45 & 1.20 & 1.80 & 0.84 \\
\hline 1034 & $0101 / 1501$ & $\mathrm{n} / \mathrm{a}$ & 1.34 & 1.10 & 1.47 & 1.70 & 2.20 & 1.20 \\
\hline 1031 & 0301 & $\mathrm{n} / \mathrm{a}$ & 0.82 & 1.18 & 1.04 & 1.30 & 0.98 & 1.30 \\
\hline 1138 & $0401 / 1101$ & $\mathrm{n} / \mathrm{a}$ & 1.22 & 1.05 & 1.07 & 1.40 & 1.55 & 1.43 \\
\hline
\end{tabular}

INF- $\gamma$ and IL-4 values represent ratios between peptide-induced SFC and negative control SFC (spot forming cells). Average SFC ratio for the PHA stimulated positive control $=10$.

$\mathrm{n} / \mathrm{a}=$ Not applicable in antibody negative subjects.

\section{Secretion of cytokines by PBMCs incubated with test peptides}

Peptides aa 1-10, aa 11-24 and aa 1-24 were tested in the interferon-gamma and IL-4 ELISPOT assays. Interferongamma and IL-4 SFC ratios for all three peptides were low in antibody-negative subjects, ranging from 0.74 to 2.20. The amino-terminal peptide aa 1-10 did not stimulate PBMCs from the antibody-positive subjects either, judged by the low interferon-gamma (0.66-1.88) and IL-4 (0.52-1.75) SFC ratios (Table 2). These low aa 1-10 SFC ratios in the antibody-positive subjects were not significantly different from those observed in the antibody-negative subjects. However, the carboxy-terminal peptide aa 11-24 caused significant stimulation of PBMCs from antibody-positive subjects judged by the secretion of both interferon-gamma and IL-4. The interferon-gamma SFC ratios in the antibodypositive subjects ranged from 0.76 to 26.00 whereas the IL4 SFC ratios ranged from 0.83 to 89.00 . The whole aa $1-24$ peptide also stimulated secretion of both interferon-gamma and IL4 in antibody-positive subjects. The interferon-gamma SFC ratios ranged from 1.53 to 34.52 and the IL4 ratios ranged from 1.18 to 92.40 (Table 2). These aa 11-24 and aa 1-24 interferon-gamma and IL4 SFC ratios observed in antibody-positive subjects were significantly higher $(P<0.05)$ from their respective counterparts observed in antibody-negative subjects.

Individual HLA haplotypes, antibody level and cytokine SFC ratios for all three peptides are summarized for antibodypositive and antibody-negative subjects in Table 2. All HLA alleles represented in the EpiMatrix epitope prediction panel except DRB $1{ }^{*} 0801$ were found in various combinations in 15 tested subjects. In addition, 7 new alleles (DRB1*1104, *1503, *0404, *0103, *0405, *1701 and *1401) were found between antibody-positive and 2 (DRB $\left.{ }^{*} 0102\right)$ among antibody-nega- tive subjects (Table 2). A more pronounced PBMC responses to both aa 11-24 and aa 1-24 peptides were observed in subjects with haplotypes DRB1*0701/1501 in subject 1038 followed by ${ }^{*} 0101 / 1301$ in subject $1128,{ }^{*} 0101 / 1701$ in subject 1163 and 0405/0101 in subject 1060 in a descending order. The haplotype DRB1*0701/1501 was associated not only with the highest PBMC response but also with the highest antibody level. A group of five antibody-positive subjects with haplotypes *0301/0701 in subject 1148 , *0301/1101 in subject 1109 , *0101/0103 in subject $1070,{ }^{*} 0101 / 1401$ in subject 1122 and ${ }^{*} 0401$ in subject 1153 showed a moderate to low PBMC activation with peptides aa 11-24 and aa 1-24. Finally, two antibody-positive subjects with haplotypes, *1104/1503 in subject 1120 and *0404/1501 in subject 1131 , as well as all four antibody-negative subjects showed virtually no PBMC activation with peptides aa 11-24 and aa 1-24. The amino-terminal peptide aa 1-10 caused no activation across the board irrespective of HLA haplotype or antibody status (Table 2 ).

\section{Discussion}

This study describes immune responses to a recombinant Fc fusion protein (FPX) in healthy human subjects. The FPX molecule is a fusion molecule consisting of human germ line Fc $\gamma$ fragment and two identical, biologically active, 24amino-acid peptides which are attached to the aminoterminal end of the Fc fragment.

The 24-amino-acid peptide subunit of FPX was analyzed for potential immunogenicity using the EpiMatrix computer algorithm that predicts binding between the 9-mer peptide sequences and eight common MHC Class II molecules and, consequently, probability of such sequences to be presented by APCs as T-cell helper epitopes. Overall, 17 allele-specific 9-mer frames showed EpiMatrix Z scores above the 
predetermined cutoff value of 1.64 and 6 scored above 2.32, which placed them in the top $1 \%$ range of the $Z$ score distribution. All of these 6 highly scoring frames were located in the carboxy-terminal region of the peptide comprising amino acids 11-23. Furthermore, the carboxy-terminal region scored highly with five of eight common separate HLA molecules suggesting that this peptide had the potential to be presented by five different HLA molecules to T-cells. This pattern is characteristic of promiscuous epitopes that are immunogenic for a broad cross-section of individuals in any human population [26].

The antibody response to FPX was consistent with high immunogenicity predicted by EpiMatrix. Following a single injection, $37 \%$ of dosed subjects developed anti-FPX antibodies. Subcutaneous administration resulted in somewhat higher (40\%) incidence of antibody response, when compared to the IV dosing (33\% of subjects). All subjects characterized by isotyping were positive for IgG indicating that the antibody response was T-cell-dependent and that isotype switching had occurred. No other antibody isotypes were detected. The association and dissociation profiles inferred from the BIAcore sensorgrams demonstrated relatively fast on- and slow off-rates in all characterized patients (data not shown). Such a binding profile is characteristic of highaffinity antibodies, which further supports a mature T-celldriven antibody response.

In vitro PBMC activation by the FPX peptide and its fragments was measured by the number of IFN- $\gamma$ and IL-4 SFCs using ELISPOT assays. It has been established that interferon-gamma and IL-4 SFCs observed using PBMCs, in fact represent activation of CD-4+ T-helper lymphocytes [27]. Both carboxy-terminal peptide aa 11-24 comprising high scoring sequences (i.e., immunogenic peptide) and the whole aa 1-24 peptide induced activation of PBMCs indicating the presence of peptide-specific memory T-lymphocytes in the majority of antibody-positive subjects. Neither the aa 11-24 nor aa 1-24 peptide induced PBMC activation in antibody-negative subjects. The amino-terminal aa 1-10 peptide containing no positive EpiMatrix scoring sequences (i.e., non-immunogenic peptide) induced no PBMC activation in antibody-positive or antibody-negative subjects.

The antibody data demonstrating a strong T-cell-driven response, as well as PBMC activation results provide evidence that the in silico prediction of immunogenic T-cell helper epitope(s) within the carboxy-terminal region of the FPX peptide was correct. Furthermore, results of the HLA typing confirmed the predicted promiscuity of carboxyterminal epitope(s), as all of the eight common HLA alleles were found in antibody-positive subjects. It should be also pointed out that the magnitude of the immune response appeared to have been dependent on the HLA haplotype. For example, subject 1038 who had the DRB1*0701 allele had the highest antibody concentration as well as number of INF- $\gamma$ and IL4 SFCs. Another subject who had DRB1*0701 allele (1148), also showed relatively high antibody concentration with a lower, but measurable SFCs. The carboxy-terminal region of the FPX peptide showed the highest EpiMatrix binding score with the DRB $1{ }^{*} 0701$ allele. In contrast, the DRB1*0301 allele appeared to be associated with very low EpiMatrix binding scores, negligible SFCs and a lack of an antibody response. Barbosa et al. [14] have also discovered an association between HLA DRB1*0701 allele and strong antibody response to recombinant beta-interferon. It should be pointed out that antibody and PBMC samples were taken at different time points in this study (i.e., Day 42 and 6 months respectively). This could have caused discrepancies between antibody levels and T-cell responses observed in some antibody-positive subjects. Combining epitope mapping with HLA haplotyping, as described in this study, may also allow researchers to screen clinical cohorts for subjects that are at higher risk for developing anti-drug antibodies.

This study also supports the precept that potential T-cell epitopes are not randomly distributed throughout protein sequences but instead tend to be clustered. These regions of unusually high binding potential are called "T-cell epitope clusters". Epitope clusters range from 9 to roughly 25 amino acids in length and, considering their affinity to multiple alleles and across multiple frames, can contain anywhere from 4 to 40 binding motifs [28]. It should be kept in mind that an accurate assessment of the peptide binding potential to the MHC Class II molecules represents only a part of an accurate prediction of actual T-cell epitopes. The endosomes and lysosomes of APCs host the processing and assembly reactions that result in the display of peptides on $\mathrm{MHC}$ Class II molecules [29]. It is conceivable that some peptides with the high Class II binding potential will be actually presented by APCs while others may never be displayed, depending on the processing of a particular protein. It appears that the FPX, with its two identical 24-amino-acid peptides attached to the germ line Fc $\gamma$ fragment was processed in a way that resulted in effective presentation of the carboxy-terminal aa 11-23 fragment comprising promiscuous T-cell epitope(s).

The T-cell-dependent antibody formation is one of the most important mechanisms for induction of antibodies in general [7]. In case of therapeutic proteins, two additional immunogenic factors include inadvertent contamination of the protein therapeutic with proinflammatory molecules and formation of protein aggregates [30]. Therapeutic protein manufacturers have developed methods for addressing the latter mechanisms, including improved purification of the recombinant protein and careful formulation of the therapeutic product. However, the first mechanism, which involves interaction between the cellular and humoral immune systems and the presentation of protein-derived epitopes bound to HLA, remains a challenge in the development of therapeutic proteins.

This study demonstrates that epitope-mapping tools such as EpiMatrix can be used to identify Class II restricted T-cell epitopes contained within therapeutic proteins that have the potential to drive an IgG response. Such in silico tools have the potential to be applied at every stage of the protein therapeutics pipeline from identification of lead candidates to characterization of immunogenicity in clinical trials participants. While more extensive validation is still needed, this and a few other studies $[14,16]$ indicate that T-cell epitope prediction will be useful not only in vaccine development but also in prospective engineering and re-engineering of protein therapeutics, reducing the risk of immunogenicity and improving the likelihood of success in clinical use.

\section{References}

[1] A.S. Rosenberg, Immunogenicity of biological therapeutics: a hierarchy of concerns, Dev. Biol. (Basel) 112 (2003) 15-21. 
[2] N. Casadevall, J. Nataf, B. Viron, A. Kolta, J.J. Kiladjian, P. Martin-Dupont, T. Papo, V. Ugo, I. Teyssandier, B. Varet, P. Mayeux, Pure red-cell aplasia and antierythropoietin antibodies in patients treated with recombinant erythropoietin, $\mathrm{N}$. Engl. J. Med. 346 (2002) 469-475.

[3] S.J. Swanson, J. Ferbas, P. Mayeux, N. Casadevall, Evaluations of methods to detect and characterize antibodies against recombinant human erythropoietin, Nephron, Clin. Pract. 96 (2004) 88-95.

[4] J. Li, C. Yang, Y. Xia, A. Bertino, J. Glaspy, M. Roberts, D.J Kuter, Thrombocytopenia caused by the development of antibodies to thrombopoietin, Blood 98 (2001) 3241-3248.

[5] F. Baert, M. Noman, S. Vermeire, G. Van Assche, G. D'Haens, A. Carbonez, P. Rutgeerts, Influence of immunogenicity on the long-term efficacy of infliximab in Crohn's disease, N. Engl. J. Med. 348 (2003) 601-608.

[6] D. Kuter, Clinical Aspects of Anti-drug Antibodies, AAPS National Biotechnology Conference, Boston, MA, 2006 (June 18-21).

[7] R.H. Zubler, Naive and memory B cells in T-cell-dependent and T-independent responses, Springer, Semin. Immunopathol. 23 (2001) 405-419.

[8] A.S De Groot, J.A. Berzofsky, From genome to vaccine - new immunoinformatics tools for vaccine design, Methods 34 (2004) 425-428.

[9] Bioinformatics in vaccine design, in: A.S. De Groot, J.A. Berzofsky (Eds.), Methods, vol. 34, 2004, pp. 425-501.

[10] A.S. De Groot, H. Sbai, C. Saint-Aubin, J.A. McMurry, W. Martin, Immuno-informatics: mining genomes for vaccine components, Immunol. Cell Biol. 80 (2002) 255-269.

[11] J.D. Ahlers, T. Takeshita, C.D. Pendleton, J.A. Berzofsky, Enhanced immunogenicity of HIV-1 vaccine construct by modification of the native peptide sequence, Proc. Natl. Acad. Sci. U. S. A. 30 (1997) 10856-10861.

[12] L. Klee, R. Zand, Probable epitopes: relationships between myelin basic protein antigenic determinants and viral and bacterial proteins, Neuroinformatics 2 (2004) 59-70.

[13] A.S. De Groot, P.M. Knopp, W. Martin, De-immunization of therapeutic proteins by T-cell epitope modification, Dev. Biol. (Basel) 122 (2005) 171-194.

[14] M.D. Barbosa, J. Vielmetter, S. Chu, D.D. Smith, J. Jacinto, Clinical link between MHC Class II haplotype and interferonbeta (IFN-beta) immunogenicity, Clin. Immunol. 118 (2006) 42-50.

[15] M. Stickler, N. Rochanayon, O.J. Razo, J. Mucha, W. Gebel, N. Faravashi, R. Chin, S. Holmes, F.A. Harding, An in vitro human cell-based assay to rank the relative immunogenicity of proteins, Toxicol. Sci. 77 (2003) 280-289.

[16] S. Tangri, B.R. Mothe, J. Eisenbraun, J. Sidney, S. Southwood, K. Briggs, J. Zinckgraf, P. Bilsel, M. Newman, R. Chesnut, C. Licalsi, A. Sette, Rationally engineered therapeutic proteins with reduced immunogenicity, J. Immunol. 174 (2005) 3187-3196.

[17] J. Oliner, et al., Suppression of angiogenesis and tumor growth by selective inhibition of angiopoietin-2, Cancer Cell 6 (2004) 507-516.

[18] A.S. De Groot, B.M. Jesdale, E. Szu, J.R. Schafer, An interactive web site providing MHC ligand predictions: application to HIV research, AIDS Res. Hum. Retroviruses 13 (1997) 539-541.

[19] J.A. Schafer, B.M. Jesdale, J.A. George, N.M. Kouttab, A.S. De Groot, Prediction of well-conserved HIV-1 ligands using a matrixbased algorithm EpiMatrix, Vaccine 16 (1998) 1880-1884.

[20] S. Southwood, J. Sidney, A. Kondo, M. Guercio, E. Appella, S. Hoffman, R. Kubo, R.W. Chestnut, H.M. Grey, A. Sette, Several common HLA-DR types share largely overlapping peptide binding repertoires, J. Immunol. 160 (1998) 3363-3373.

[21] A.S. De Groot, B.M. Jesdale, Several common HLA-DR types share largely overlapping peptide binding repertoires, AIDS Res. Hum. Retroviruses 13 (1997) 539-541.

[22] A.S. De Groot, A. Bosma, N. Chinai, J. Frost, B.M. Jessdale, A. Gonzales, W. Martin, C. Saint-Aubin, From genome to vaccine: in silico predictions; ex vivo verification, Vaccine 19 (2001) $4385-4395$.

[23] A.S. De Groot, B. Jesdale, W. Martin, C. Saint-Aubin, H. Sbai, A. Bosma, J. Lieberman, G. Skowron, F. Mansourati, K.H. Mayer, Mapping cross-clade HIV-1 vaccine epitopes using a bioinformatics approach, Vaccine 21 (2003) 4486-4504.

[24] S.J. Swanson, J. Ferbas, et al., Evaluation of methods to detect and characterize antibodies against recombinant human erythropoietin, Nephron. Clin. Pract. 96 (2004) 88-95.

[25] S. Mason, S. La, D. Mytych, S.J. Swanson, J. Ferbas, Validation of the BIACORE 3000 platform for detection of antibodies against erythropoietic agents in human serum samples, Curr. Med. Res. Opin. 9 (2003) 651-659.

[26] L.K. Iwai, M. Yoshida, J. Sidney, M.A. Shikanai-Yasuda, A.C. Goldberg, M.A. Juliano, J. Hammer, L. Juliano, A. Sette, J. Kalil, L.R. Travassos, E. Cunha-Neto, In silico prediction of peptides binding to multiple HLA-DR molecules accurately identifies immunodominant epitopes from gp43 of paracoccidioides brasiliensis frequently recognized in primary peripheral blood mononuclear cell responses from sensitized individuals, Mol. Med. 9 (2003) 209-219.

[27] T. Helms, B.Q. Boehm, R.J. Assad, R.P. Trezza, P.V. Lehmann, M. Tary-Lehmann, Direct visualization of cytokine producing recall antigen specific CD4+ memory Tcells in healthy individuals and HIV patients, J. Immunol. 164 (2000) 3723-3732.

[28] P. Panina-Bordignon, A. Tan, A. Termijtelen, S. Demotz, G. Corradin, A. Lanzavecchia, Universally immunogenic $T$ cell epitopes: promiscuous binding to human MHC Class II and promiscuous recognition by T cells, Eur. J. Immunol. 19 (1989) 2237-2242.

[29] C. Watts, The exogenous pathway for antigen presentation on major histocompatibility complex Class II and CD1 molecules, Nat. Immunol. 5 (2004) 685-692.

[30] A.S. Rosenberg, A.S. Worobec, A risk-based approach to immunogenicity concerns of therapeutic protein products, BioPharm Int. 34-44 (Suppl 1) (2004) S20. 